\title{
Individual Talker and Token Covariation in the Production of Multiple Cues to Stop Voicing
}

\author{
Meghan Clayards \\ Department of Linguistics, School of Communication Sciences and Disorders, \\ McGill University, Montreal, QC, Canada
}

\begin{abstract}
Background/Aims: Previous research found that individual talkers have consistent differences in the production of segments impacting the perception of their speech by others. Speakers also produce multiple acoustic-phonetic cues to phonological contrasts. Less is known about how multiple cues covary within a phonetic category and across talkers. We examined differences in individual talkers across cues and whether token-by-token variability is a result of intrinsic factors or speaking style by examining within-category correlations. Methods: We examined correlations for 3 cues (voice onset time, VOT, talker-relative onset fundamental frequency, f0, and talker-relative following vowel duration) to word-initial labial stop voicing in English. Results: VOT for /b/ and /p/ productions and onset fo for $/ b$ / productions varied significantly by talker. Token-by-token within-category variation was largely limited to speaking rate effects. VOT and f0 were negatively correlated within category for $/ \mathrm{b} /$ productions after controlling for speaking rate and talker mean f0, but in the opposite direction expected for an intrinsic effect. Within-category talker means were correlated across VOT and vowel duration for $/ \mathrm{p} /$ productions. Some talkers produced more prototypical values than others, indicating systematic talker differences. Conclusion: Relationships between cues are mediated more by categories and talkers than by intrinsic physiological relationships. Talker differences reflect systematic speaking style differences.
\end{abstract}

(C) 2017 S. Karger AG, Basel

\section{Introduction}

\subsection{Multiple Cues}

Every phonological contrast has a multitude of phonetic correlates, many of which have been demonstrated to affect perception (Raphael, 2005). Throughout this paper

\section{KARGER \\ E-Mail karger@karger.com www.karger.com/pho}

(C) 2017 S. Karger AG, Basel

\section{Meghan Clayards}

Department of Linguistics, McGill University

School of Communication Sciences and Disorders

2001 McGill College, 8th Floor, Montreal, QC H3A 1G1

(Canada), E-Mail meghan.clayards@mcgill.ca 
we will refer to these phonetic correlates as "cues" when they have been demonstrated to have an effect on perception. As an example, Lisker (1986) pointed out that there are many potential cues to word-medial voicing in English (e.g. "rapid" - "rabid") such as duration of the preceding vowel, duration of the closure, voice onset time (VOT), presence of vocal fold vibration during closure, burst amplitude, fundamental frequency (f0) going into and out of the closure (offset and onset f0) and first formant frequency going into and out of the closure. Such multiple correlates to phonological contrasts or categories are in fact ubiquitous and perhaps unsurprising given the complex acoustic consequences of a dynamically changing and complex sound generation system such as the vocal tract. A classic literature in speech perception using synthetic speech stimuli has also demonstrated that many acoustic variables contribute to our percepts of stop place of articulation (e.g. Bailey and Summerfield, 1980), stop voicing (e.g. Port and Dalby, 1982), fricative place of articulation (e.g. Mann and Repp, 1980), and many other contrasts. These studies found that the perceptual effect of changes in the value of one cue (e.g. lengthening closure duration in a word-medial stop) can be offset by changes in the value of another cue (e.g. lengthening the preceding vowel), a phenomenon termed trading relations (see Repp, 1982, for a review and Toscano and McMurray, 2010, for further discussion). Thus, many acoustic dimensions "make up" phonological categories. While the literature on perceptual trading relations has explored how multiple cues work together in perception, we know much less about how acoustic cues pattern together in the speech signal itself especially within phonological categories and across talkers. This paper explores one fundamental aspect: to what extent are cues in the speech signal independent of each other and to what extent are they intrinsically linked at the level of the category and at the level of the talker?

We know that cues covary across categories. For example, in English, voiceless stops before stressed vowels have long VOTs and relatively high f0 in the onset of the following vowel while voiced stops have short VOTs and relatively low f0 in the following vowel (House and Fairbanks, 1953; Lehiste and Peterson, 1961; Lisker and Abrahmson, 1964; Umeda, 1981; Ohde, 1984). That is, VOT and f0 are positively correlated across voicing categories. However, it is a separate question whether within categories (e.g. within voiceless stops) a longer VOT is associated with a higher f0. In other words, are they still correlated conditional on the category? Conversely, an analogue of perceptual trading relations could exist in production. In other words, when a speaker produces an ambiguous value of a cue (e.g. a VOT intermediate between what is expected for voiced and voiceless stops) they could compensate by producing a more extreme value of another cue (e.g. a very high f0). The first goal of this paper is to examine these possible relationships between cues on a token-by-token basis within category, discussed further in Section 1.2 below. Either of the patterns described above would have implications for our understanding of speech production as well as speech perception. Another possibility is that there are relationships between cues not on a token-by-token basis, but on a talker-by-talker basis as discussed in Section 1.3 below. The second goal of this paper is to examine these individual talker differences.

\subsection{Token-by-Token Variation of Multiple Cues within Categories}

There are good reasons to think that some cues could covary on a token-by-token basis - that is when we examine individual productions of a single category we might find correlations between cues. If, for example, 2 cues share a single articulatory or aerodynamic source, then one would expect that they would be inextricably linked in 


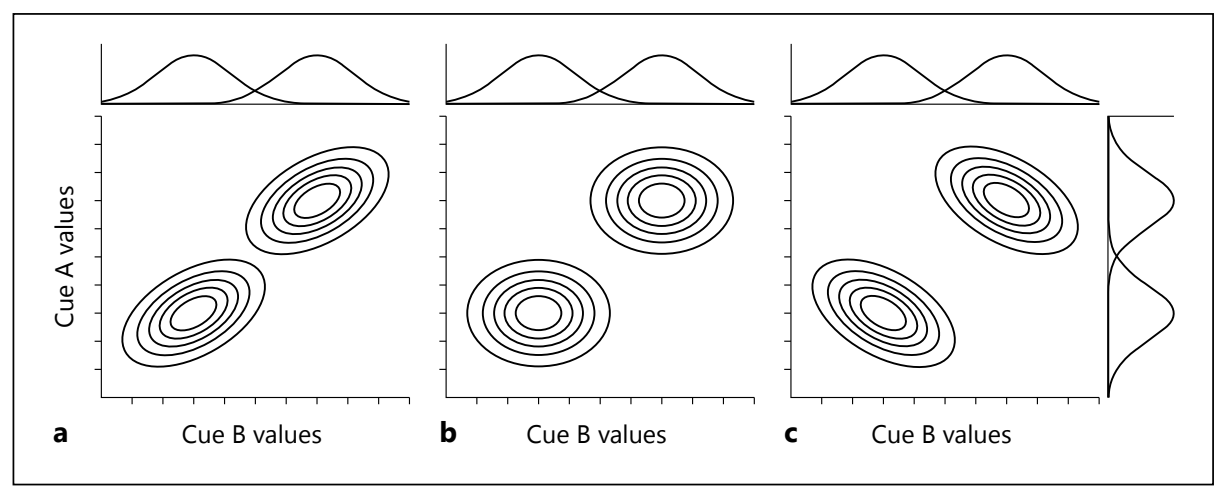

Fig. 1. Hypothetical distributions of 2 cues to 2 categories showing 3 possible relationships between the cues: token-by-token within-category correlations with a possible intrinsic source (a), uncorrelated within category (b), within-category correlations with "cue trading" (c). Ellipses represent equal probability lines of multivariate distributions. Distributions for each individual dimension are represented as continuous histograms above and to the right of the 3 panels.

production - intrinsically linked according to the terminology of Wang and Fillmore (1961). For example, if lowering the velum has the effect of lowering the amplitude of the signal as well as increasing the bandwidth of the formants, then one might expect the degree of amplitude reduction and the amount of increase in bandwidth to be correlated. Similarly it has been argued that lowering the larynx to facilitate voicing by increasing supraglottal volume also decreases the stiffness of vocal folds, thus lowering onset f0 (Hombert et al., 1979; Hoole et al., 2004; Hoole and Honda, 2011). In this situation we would expect these cues to exhibit a correlation on a token-by-token basis within category as well as between categories, and we would expect these correlations within and between categories to be in the same direction as in Figure 1a.

On the other hand, not all of the multiple cues associated with a particular contrast need to be produced by a single articulatory movement. For the production of intervocalic Dutch stops, Slis and Cohen (1969) argue on the basis of articulatory data that the movements and musculature responsible for the timing of the oral closure (supraglottal gestures) - which govern such cues as the duration of the closure interval and the duration of the preceding vowel - are independent from the movements and musculature responsible for the timing of voicing (glottal gestures) - and thus onset f0, amount of voicing during closure and time to voice onset (but see Ohde, 1984, for counterarguments). Thus, some of the cues involved in voicing (at least in Dutch) may be independent of one another on a token-by-token basis, while others may not be. It has also been noted that the category correlation between voicing and onset $\mathrm{f} 0$ holds across languages despite very different implementations of the voicing contrast (e.g. Dmitrieva et al., 2015; see Kirby and Ladd, 2016 for a recent review of reasons for covariation between VOT and onset f0).

Based on cross-linguistic patterns and articulatory evidence, Kingston and Diehl (1994) have argued that many cues are not automatic consequences of primary articulatory gestures but are under the control of the speaker, although not necessarily conscious control. The listener may then learn to associate these cues and thus produce them together (Nearey, 1997; Holt et al., 2001). Or, alternatively, speakers may produce these cues because they cohere or integrate for auditory reasons as argued by Kingston 
and Diehl (1994) and colleagues. In their view, these cues also serve to enhance the perception of the contrast by contributing to intermediate perceptual properties (Kingston and Diehl, 1994; Kingston et al., 2008). For example, in voicing contrasts, they argue that lowered $\mathrm{f0}$ and voicing during closure both contribute to an intermediate perceptual property of low-frequency energy continuity (Kingston et al., 2008). Thus, the lower f0 at the stop closure enhances the percept of voicing beyond what the vocal fold vibration contributed. The possibility that speakers of a language (unconsciously) choose to covary cues in order to enhance perception (i.e. low f0 for voiced stops and higher for voiceless ones) would imply a relationship between them that is not necessarily intrinsic to the articulatory system. That is, we expect the between-category correlations that we know exist between cues, but there is no reason to expect withincategory correlations as illustrated in Figure 1a. Instead we might expect a pattern like in Figure $1 \mathrm{~b}$. In this pattern the cues are correlated across categories but independent within the categories (conditionally independent).

Alternatively, if cues are produced together for perceptual reasons (either due to intermediate perceptual property processes or simply to provide redundancy in the signal), speakers might use one cue to compensate for ambiguities created by another cue. For example, if a speaker intended to produce a voiceless stop but produced a VOT that is shorter than is prototypical for such a stop, they might also increase f0 in order to make sure that they conveyed the intended message to the listener. This strategy would essentially take advantage of trading relations in perception where a less ambiguous cue in one dimension can compensate for a more ambiguous cue in another dimension. Note that such a production strategy does not depend on the perceptual interactions described by Kingston and Diehl and colleagues discussed above. Even if cues do not perceptually cohere, and even if cues are not correlated in any way within categories in production, multiple cues will produce trading relations in perception, as long as listeners attend to the cues to make judgments about categories (see Clayards, 2008; Toscano and McMurray, 2010). However, if speakers adopted a compensatory strategy in production, one would expect that ambiguous values of one cue would tend to co-occur with more extreme values of another, creating withincategory correlations as illustrated in Figure 1c in which the within-category correlations are in the opposite direction of the between-category correlation. It should also be noted that even if speakers are not able to modulate cues on a token-by-token basis in production, they might do so on an individual basis. In other words, a talker who tends to use VOT more distinctively may use f0 less or vice versa. This would also tend to create the pattern in Figure 1c; however, it would be true of talker means, not of token-by-token variability. Patterns due to talker means are discussed further in Section 1.3.

In summary, there are reasons to expect any of the 3 within-category patterns. Cues could be linked intrinsically in the articulatory system creating within-category patterns in the same direction as the between-category patterns; cues could be independent within categories despite being correlated between categories; cues could be produced in a compensatory way on a token-by-token basis creating within-category correlations in the opposite direction from the between-category correlation. Observing any of these patterns would tell us more about the mechanisms that determine the internal structure of categories. However, another important source of variability in speech is not just categories but also talkers, and the relationship between cues may be closely linked to the individuals who produced them. 


\subsection{Individual Differences in Production}

There is a growing literature on individual differences in production and perception of speech. Here we focus on production differences and their consequences for speech perception by other listeners. Research has shown that individual talkers are distinct in their production of phonetic cues. Newman et al. (2001) showed that individuals can have very different productions of sibilants, and that in some cases the distribution of the spectral centre of gravity for /s/ of one talker overlaps entirely with / $/$ / for another talker. They also found that talkers differed in how much the 2 categories overlapped, and that the degree of overlap had consequences for how well listeners were able to recognize the sounds. VOTs in English are known to be systematically different between talkers, including the amount of prevoicing and the amount of voicing lag (e.g. Allen et al., 2003; Scobbie, 2006) even when controlling for speaking rate, while Theodore et al. (2009) found that speaking rate effects on VOT were also talker specific. McMurray and Jongman (2011) investigated talker effects in fricative production and found significant effects of talker on almost every cue investigated. Individual differences have also been demonstrated for articulatory data (e.g. Johnson et al., 1993) which can result in different acoustics (Noiray et al., 2014). Thus, variability in production is well documented and has consequences for listeners.

While individual talker differences have been shown to impact on how easily some talkers are understood (Newman et al., 2001; Ferguson, 2004; Hazan and Markham, 2004), there is also an advantage for listening to talkers that are familiar (Nygaard and Pisoni, 1998). Some of these advantages are tied to language-specific knowledge and so likely reflect knowledge of how variability is structured in the language (Goggin et al., 1991). This suggests that one way that listeners deal with individual talker variability is by adapting to the patterns of talkers they are exposed to. There have to date been many demonstrations that listeners do in fact adapt to the properties of the speech that they are exposed to (e.g. Bertelson et al., 2003; Norris et al., 2003), and this may be tied to individual talkers (Eisner and McQueen, 2005). Theodore and colleagues (Theodore and Miller, 2010; Theodore et al., 2015) showed that listeners are sensitive to talker differences in VOT and can generalize expectations about talker VOT to novel tokens. Because speech is highly multidimensional - even for a single contrast, and there are many phonological contrasts - tracking and adapting to each of these dimensions for each talker seems like a daunting task for any listener. One possibility is that these dimensions do not vary randomly between talkers but instead bear a systematic relationship. For example talkers with relatively long VOTs in voiceless stops could have relatively high $\mathrm{f0}$ in those stops as well (analogous to the pattern in Fig. 1a, but for talker means instead of tokens). Conversely, talkers who signal voicing relatively more consistently with VOT may use f0 relatively less consistently (analogous to the pattern in Fig. 1c, but for talker means instead of tokens). This would greatly simplify the task for the listener as it would require them to identify some aspect of the variation in order to predict many other aspects. Thus, the second goal of this paper is to examine how cues vary across talkers within a single phonetic category and across phonetic categories within a voicing contrast.

\subsection{Present Study}

The present study examined 3 acoustic cues to voicing in voiced and voiceless word-initial monosyllabic labial stops (e.g. beach and peach) - VOT, f0 at vowel onset, and length of the following vowel. We included following vowel duration as a cue to 
voicing although it has been argued to be cue to speaking rate that should be interpreted relative to VOT (e.g. Kohler, 1979; Boucher, 2002) as it seems to play an independent role in perception of voicing (McMurray et al., 2008; Toscano and McMurray, 2012). Vowel duration is also used as a measure of speaking rate as a control variable in evaluating the other 2 cues as it is known to affect VOT especially in /p/ productions (Miller et al., 1986).

Very few studies have reported on the correlations of cues within categories. One well-known example is locus equations, which demonstrate very high correlations for $\mathrm{f} 2$ at vowel onset and $\mathrm{f} 2$ at vowel midpoint within a single stop category but across vowels (Sussman et al., 1998). However, it is not clear whether this constitutes a particular kind of contextual variation (different from the within-category variation of interest here) or a single integrated cue for the listener. Most relevant to the current paper, a recent study by Dmitrieva et al. (2015) examined correlations between VOT and onset $\mathrm{f0}$ for Spanish and English. They found a weak negative trend between VOT and onset f0 for voiceless stops in English (longer VOTs with lower f0) and a weak positive correlation for voiced stops in English (shorter VOTs with lower f0). A second recent study examined correlations between VOT and onset $\mathrm{fO}$ in French and Italian stops. Kirby and Ladd (2015) found the same pattern in voiceless Italian stops as Dmitrieva et al. (2015) found for English, i.e. longer VOTs with lower f0, but no correlations for French. In both Italian and French, negative VOTs occur with voiced stops, and the researchers found that longer voicing lead was correlated with lower f0. Together these two studies have generally found a negative relationship between f0 and VOT for voiceless stops and a positive relationship for voiced stops, though for some languages there was no relationship. However, there is an important limitation to these results in that differences between individuals were only partially considered - $\mathrm{f0}$ measurements were normalized to talkers' overall means; however, differences in individual talkers' VOTs were not considered and are crucial to understanding the patterns.

If the 2 cues were intrinsically linked by articulatory mechanisms, we would expect the pattern in Figure 1a for each individual talker. However, differences in mean values of the cue across talkers could obscure the relationship when pooling across talkers. For example, for any given talker, a relationship like in Figure 1a could hold, but if talkers have different average VOTs (as has been shown, see above), the group data could look like in Figure 1b. Similarly, an apparent relationship between the cues across talkers could be due to differences in mean values between talkers. For example, some talkers could produce large differences in cue values for the 2 categories for both cues while others produce smaller differences for both cues. If we then pooled across talkers, a pattern like the one in Figure 1a would emerge with some talkers' productions falling towards the middle and others towards the extremes. On the other hand, talkers could instead differ in the extent to which they rely on a particular cue versus another cue to signal a contrast. This could be due to physiological differences between talkers or simply due to individual preferences. Shultz et al. (2012) used the same data as Dmitrieva et al. (2015) to examine the relationship between production cue weights for f0 and VOT for individual talkers. They used linear discriminant analysis to compute coefficients for VOT and f0 for each talker. They found a significant negative correlation between the two so that the more a given talker signalled the contrast with VOT, the less they signalled it with $\mathrm{f0}$. This trade-off relationship predicts a pattern similar to Figure 1c when the results are pooled across talkers, and this is what was reported for the voiceless category of Dmitrieva et al. (2015). Kirby and Ladd (2015) also pooled 
data across talkers. It is therefore possible that the patterns reported in both papers are due to differences in individual talkers' average VOT and average f0 rather than an intrinsic relationship between the cues. It is therefore critical to examine the behaviour of individual talkers as well as to separate talker-by-talker variation from token-bytoken variation in multiple cues. Examining how individual talkers use cues to signal the voicing contrast (i.e. across categories) will also allow us to better understand differences between talkers.

\section{Methods}

\subsection{Participants}

Nine talkers (7 female) at the University of Rochester, in Rochester, NY, USA, initially produced a set of recordings. All were native monolingual English speakers from a variety of North American dialect regions (age 23-30 years). An additional 11 talkers (3 female) were recruited from McGill University, Montreal, QC, Canada, with the same characteristics (all were native monolingual speakers of either American or Canadian English from a variety of dialect regions in the same age range) who completed the same task. The total number of talkers was 20 (10 female).

\subsection{Procedure}

Talkers read the words from index cards, repeating each word 3 times in succession. The order of cards was randomly shuffled for each talker. The cards were then reshuffled, and each word was read 3 times again in a different random order for a total of 6 recordings of each word ( 2 talkers read the list a third time, and some words had to be discarded due to speech errors or background noise resulting in slightly different numbers of tokens per talker). No carrier phrase was used. The first set of talkers (Rochester) were recorded in a sound-attenuated booth using a Marantz portable digital recorder (PMD 670) and a Technica lapel microphone worn approximately 6 inches from the mouth. Sound files were digitized at a sampling rate of $32,000 \mathrm{~Hz}$. The second set (Montreal) were recorded in a sound-attenuated booth directly onto a computer at a sampling rate of $44,100 \mathrm{~Hz}$ using Praat (Boersma and Weenink, 2011) and a Logitech H390 USB headset microphone. Four of these talkers ( 2 female) read from a longer set of words (which included 10 disyllabic words with word-medial stops not analysed here). These talkers produced all of the words in a randomized order, repeating each word 3 times when they read it as before. They repeated this procedure 10 times with a different randomized order each time. This created a total of 30 recordings for each word (some productions were again discarded due to errors, noise or recording problems). In the analyses reported here, all the data are grouped together, and mixed effects regression is used which accounts for differences in amount of data between talkers.

\subsection{Word List}

Three minimal pairs were chosen: beach, peach, bees, peas, beak and peak. Words were originally chosen to be part of a perceptual experiment and were chosen to be minimal pairs with the same vowel quality and to be picturable.

\subsection{Acoustic Measurements}

All acoustic analyses were performed using the Praat software package (Boersma and Weenink, 2011). Temporal intervals (e.g. length of the vowel) were marked by hand according to characteristic markers in the waveforms.

Both positive and negative VOTs were measured. Positive VOT was defined as the time from the beginning of the stop burst to the onset of voicing of the vowel. The onset of voicing was defined as the point where the (quasi) periodic portion of the waveform first crossed zero in the positive direction. Some speakers produced a period of voicing before the release burst. In this case, negative VOT was measured from the onset of periodic voicing until the stop burst and the period between the burst and the onset of voicing in the subsequent vowel was not analysed. 
Table 1. Means for each of the cues by voicing category and talker gender

\begin{tabular}{llllllll}
\hline & Gender & VOT, ms & f0, Hz & Vowel, ms & Final voicing & Vowel, ms \\
\hline /b/ & $\mathrm{f}$ & 2.4 & 225.4 & 206.1 & $/ \mathrm{b} /$ & voiced & 296.1 \\
& $\mathrm{~m}$ & 7.5 & 116.2 & 182.4 & & voiceless & 144.0 \\
\hline $\mathrm{p} /$ & $\mathrm{f}$ & 76.1 & 245.9 & 172.4 & $/ \mathrm{p} /$ & voiced & 266.9 \\
& $\mathrm{~m}$ & 68.0 & 125.3 & 162.5 & & voiceless & 119.8 \\
\hline
\end{tabular}

Means for vowel duration are also grouped by word-final voicing. m, male; f, female.

The onset of the vowel was always the onset of voicing. The offset of the vowel was defined differently depending on the following consonant. Before stops and affricates, the end of the vowel was the last pitch cycle before a significant drop in amplitude. Before fricatives it was the last pitch cycle before significant frication noise. Words ending in voiced consonants (bees and peas) had longer vowels than those ending in voiceless consonants (beach, beak, peach and peak; Table 1) as expected (House and Fairbanks, 1953; Mack, 1982). We therefore subtracted the mean vowel duration (averaged across talkers) for words with voiced codas from each of the words with a voiced coda and the mean vowel duration (averaged across talkers) for voiceless codas for each of the words with a voiceless coda (hereafter final-voicing-relative vowel duration). This measure was used as a measure of speaking rate in the individual difference analyses below. A second measure took account of individual differences in speaking rate. Each talker's mean vowel duration was subtracted from the final-voicingrelative vowel duration (hereafter relative vowel duration for simplicity).

Onset f0 measurements were obtained by hand-measuring the duration of the first 3 pitch cycles of the following vowel as in Cole et al. (2007). Very low-onset f0 values due to creak were removed (below $70 \mathrm{~Hz}$ ). Because men and women have different average f0 (Table 1), onset f0 was transformed to semitones relative to each talker's mean onset f0 using the formula $12 \ln$ (x/individual mean onset f0)/ln 2 (as in Schultz et al., 2012, and Dmitrieva et al., 2015). Resulting values are on a logarithmic scale accounting for higher dispersion for higher f0 values. Positive values are above the talker's mean onset $\mathrm{f0}$, and negative values are below the talker's mean onset f0.

\section{Results}

\subsection{Distribution of Cues}

A total of 1,371 tokens was analysed. Raw means for each category (untransformed) are summarized in Table 1. Figure 2 shows the smoothed density plots of each cue for each category. Vowel duration and onset $\mathrm{f} 0$ are normalized as described above (talker and voicing relative vowel duration, talker-relative semitones for onset f0). There is little overlap between the categories for VOT and considerable overlap for all other cues consistent with previous observations that VOT is the dominant cue to this contrast in word-initial position (Lisker and Abrahmson, 1964). Onset f0 is higher and following vowel shorter for $/ \mathrm{p} /$ productions as expected given the previous literature (House and Fairbanks, 1953; Lehiste and Peterson, 1961; Umeda, 1981; Ohde, 1984).

\subsection{Correlations between Cues}

We now turn to the raw correlations between cues. The left panel of Figure 3 shows measurements of VOT versus onset $\mathrm{f} 0$ for each token for the voiced and voiceless categories. The middle panel shows VOT versus relative vowel duration measurements. The right panel shows relative vowel duration measurements versus onset f0. To examine 


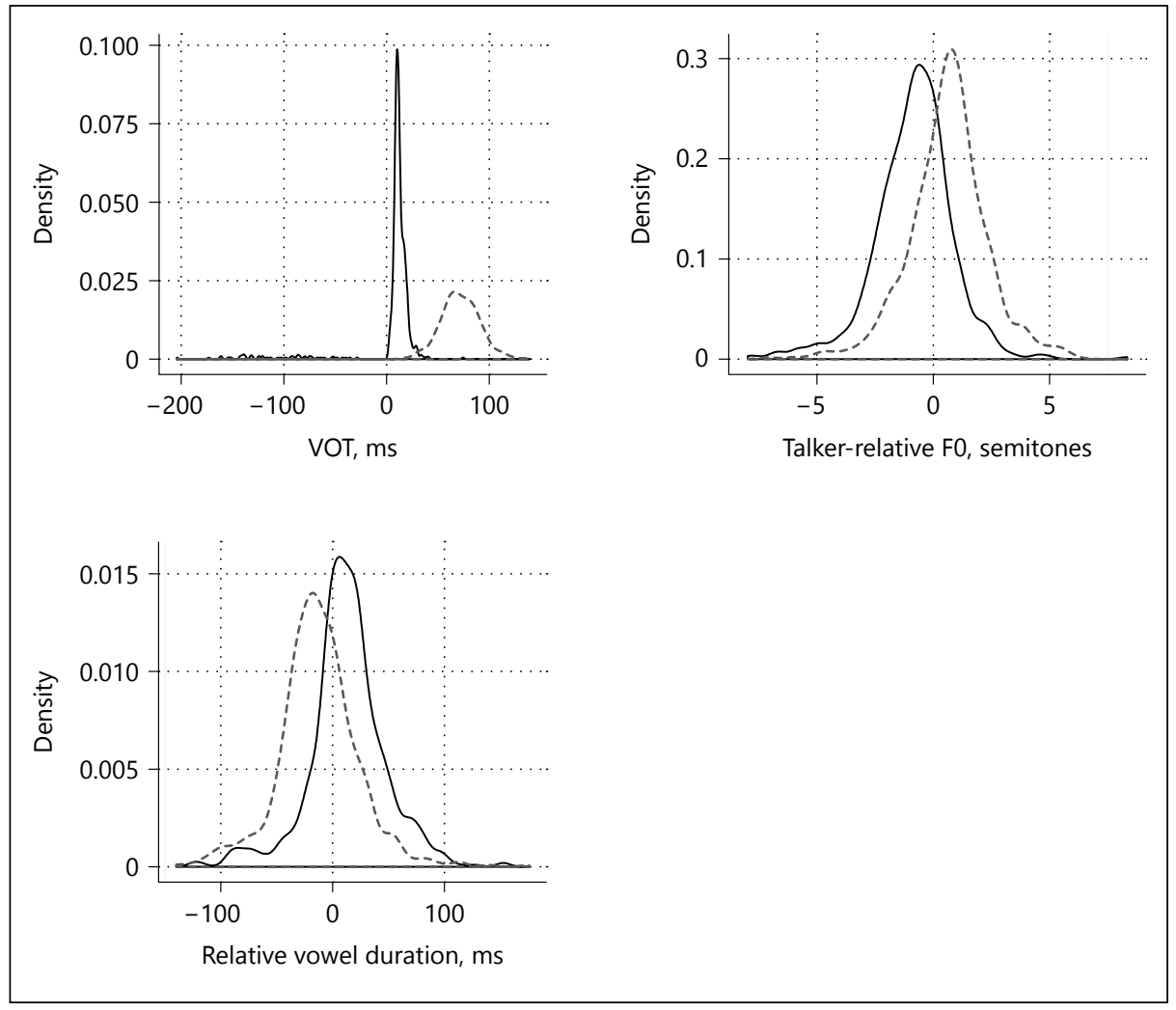

Fig. 2. Density plots smoothed with a Gaussian kernel showing the distribution of values for each cue for each category pooled across all speakers. Black lines are /b/ productions, grey dashed lines are /p/ productions. Onset f0 is normalized relative to talker mean onset f0. Vowel duration is normalized for voicing of the following consonant and talker mean duration.

the relationship between the 3 cues we began with simple correlational analysis for each token within category as was done in Dmitrieva et al. (2015) and Kirby and Ladd (2015) for VOT and onset f0. Because the prevoiced VOTs were not contiguous with the shortlag VOTs, we examined correlations for these separately (see Dmitireva et al., 2015, and Kirby and Ladd, 2015, for a discussion of reasons why prevoiced and short-lag stops may pattern differently). To see whether these correlations were in the same direction as the between-category correlation (as Fig. 1a) or in the opposite direction (Fig. 1c) the correlation between categories was also calculated. Note that in the case of the betweencategory correlations it is the sign of the correlation that is of interest and not the magnitude. The magnitude of the between-category correlation will be proportional to how well the 2 cues signal the contrast independently of each other. Because voiced stops have on average shorter VOT, lower onset f0 and longer vowel duration, we expect a positive between-category correlation between VOT and onset f0, a negative between-category correlation between VOT and vowel duration, and a negative between-category correlation between onset $\mathrm{f0}$ and vowel duration, and this is what we found (Table 2). For the within-category correlations, the sign, magnitude, and significance are all relevant. 


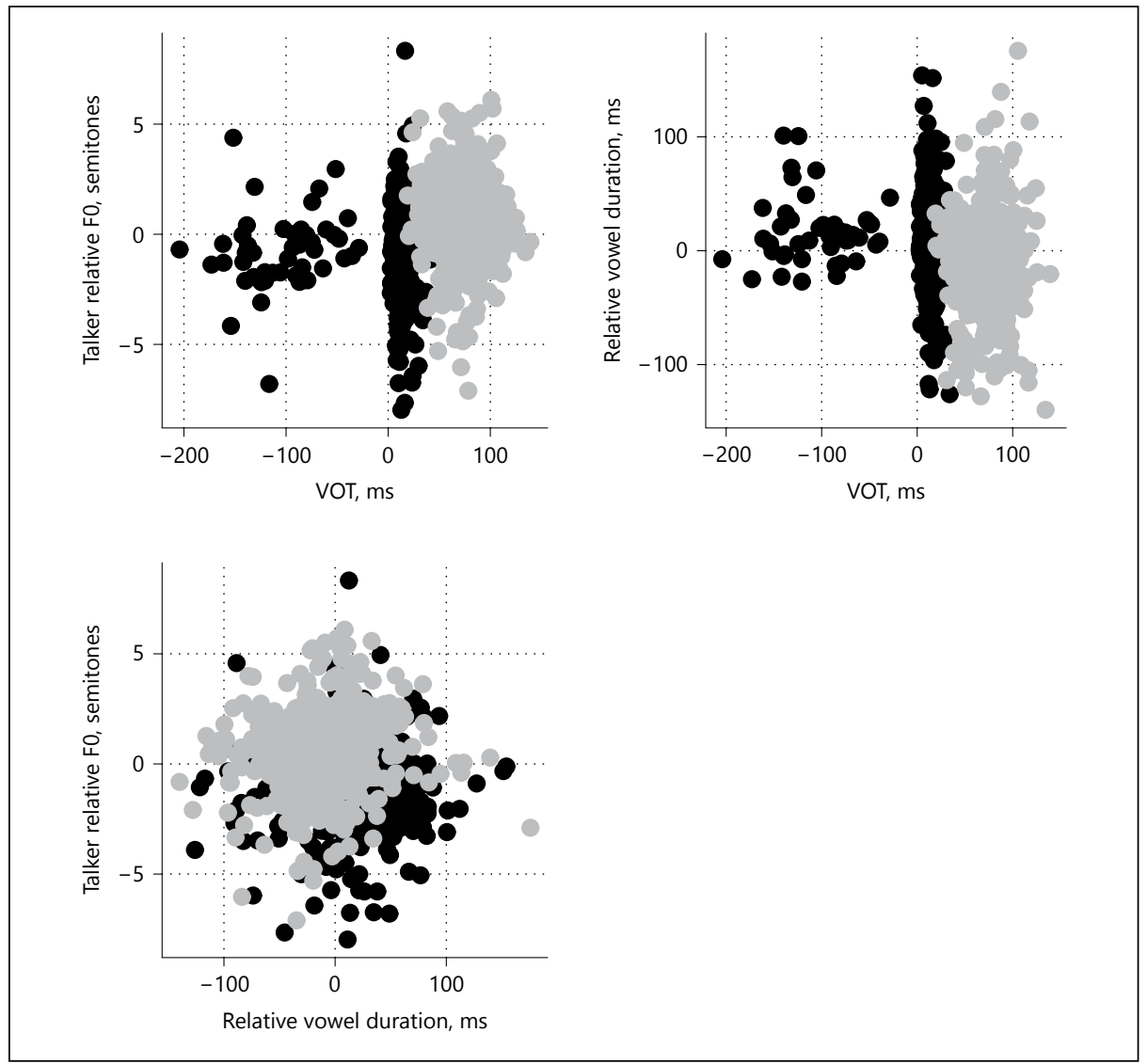

Fig. 3. Scatter plots of individual tokens for VOT, talker-relative fo and final-voicing and talker-relative vowel duration. Black circles are /b/ tokens, and grey circles are /p/ tokens.

Table 2. Pearson $R$ correlations for VOT, onset $\mathrm{f} 0$ and final voicing and talker-corrected vowel duration for each voicing category as well as both categories together

\begin{tabular}{llccr}
\hline & Data & Pearson $R$ & $p$ & \multicolumn{2}{c}{$N$} \\
\hline f0/VOT & all & 0.309 & 0.000 & 1,271 \\
& /p/ & 0.000 & 0.995 & 652 \\
& /b/+ & -0.111 & 0.008 & 573 \\
& /b/- & -0.208 & 0.160 & 47 \\
\hline Vowel duration/VOT & all & -0.280 & 0.000 & 1,366 \\
& /p/ & 0.054 & 0.158 & 686 \\
& /b/+ & -0.155 & 0.000 & 635 \\
& /b/- & -0.022 & 0.886 & 46 \\
\hline f0/vowel duration & all & -0.079 & 0.005 & 1,269 \\
& $/ \mathrm{p} /$ & 0.116 & 0.003 & 652 \\
& /b/ & 0.019 & 0.630 & 617 \\
\hline
\end{tabular}

VOT values for $/ \mathrm{b} /$ are split into positive $(+)$ and negative $(-)$ VOT values. 
Within categories, we found no correlations between VOT and f0 for the /p/ productions $(r[650]=0.00, p=0.995)$ unlike the weak negative correlation found by Dmitrieva et al. (2015) for English voiceless stops. We found a negative correlation in the $/ \mathrm{b} /$ productions between positive VOTs and onset f0 $(r[571]=-0.111, p=0.008)$ and a non-significant negative correlation for the negative VOTs $(r[45]=-0.208, p=$ 0.160 ) which should be treated with caution given the low number. These are in the opposite direction as the results of Dmitrieva et al. (2015) for English. For vowel duration and VOT there was a non-significant positive correlation within the $/ \mathrm{p} /$ productions $(r[684]=0.054, p=0.158)$. Within the $/ \mathrm{b} /$ productions there was a negative correlation for positive VOT values (longer vowels go with shorter VOTs, $r[632]=-0.155$, $p<0.001$ ) and a non-significant negative correlation for negative VOT values (longer vowels go with more negative VOTs, $r[44]=-0.022, p=0.886$ ) but again the results for negative VOTs are based on a very small sample. The positive relationship within the $/ \mathrm{p} /$ productions is consistent with a speaking rate effect, where longer vowels and longer VOTs are both part of a slower speaking rate (Kessinger and Blumstein, 1997, 1998); however, this effect was small and non-significant. Within the /b/ productions, the pattern with the negative VOT values could also be explained this way as a slower speaking rate leads to longer prevoicing (Kessinger and Blumstein, 1997). However, the pattern for positive VOT values within /b/ productions is not consistent with overall slowing as we found longer vowels occurred with shorter VOTs. Finally, onset f0 and relative vowel duration were positively correlated within $/ \mathrm{p} /$ productions $(r[650]=$ $0.116, p=0.003$ ) and showed a non-significant negative correlation within $/ \mathrm{b} /$ productions $(r[615]=0.019, p=0.630)$.

So far, none of these trends is clearly consistent with any of the panels in Figure 1 (intrinsic, compensatory or simply uncorrelated) because the within-category correlations are not consistent across the 2 voicing categories. The patterns are also inconsistent with some previous findings. However, these simple correlations do not allow us to examine whether talker differences in mean values for each category observed in the previous section are contributing to or obscuring a relationship as discussed in the introduction. The goal of the next section is to explore these relationships more fully as well as to look at individual differences in use of cues.

\subsection{Individual Differences in Individual Cues}

Before examining the question of whether cues are correlated across talkers, we first determined if there were significant talker differences between cues for each voicing category using the same modelling strategy as Allen et al. (2003). We built mixed effects regression models for each variable tested (VOT, onset f0 and relative vowel duration) using the lmer package in R (Bates et al., 2014). The models for VOT and onset f0 also included final-voicing relative vowel duration as a control measure for speaking rate. Because talkers repeated each word 3 times in a row, they may have adopted a prosodic contour that was repeated with each set of 3 . Inspection of VOT, f0 and vowel duration values according to repetition suggested that VOT increased, f0 decreased and vowel duration increased over the 3 repetitions. To control for this we added repetition as a continuous (centred) variable to the each of the models. Then, as in Allen et al. (2003), we added random intercepts for talkers to determine whether individuals reliably differ from each other in how they produced each cue. Allen et al. (2003) examined VOT for $/ \mathrm{p} /$ productions, but here we extend it to /b/ productions and to 2 other cues. As a stricter test of individual differences in $/ \mathrm{b} /$ productions, 
Table 3. Results from model comparison tests of talker differences for each cue and category for $/ \mathrm{p} /$ productions (left) and /b/ productions (right)

\begin{tabular}{llrlllrl}
\hline p/ & \multicolumn{1}{c}{$\chi^{2}(d f)$} & $p$ & /b/ & & $\chi^{2}(d f)$ & $p$ \\
\hline VOT & intercept & $210.1(1)$ & 0.00 & VOT & intercept & $66.6(1)$ & 0.00 \\
& vowel length & $1.4(1)$ & 0.23 & & $\begin{array}{l}\text { vowel length } \\
\text { repetition }\end{array}$ & $0.2(1)$ & 1.00 \\
& repetition & $0(1)$ & 1.00 & & intercept & $4.3(1)$ & 0.68 \\
\hline f0 & intercept & $0(1)$ & 1.00 & f0 & vowel length & $4.5(1)$ & 0.03 \\
& vowel length & $8.8(1)$ & 0.00 & & repetition & $25.8(1)$ & 0.00 \\
\hline Vowel & intercept & $0(1)$ & 1.00 & Vowel & intercept & $0(1)$ & 1.00 \\
& repetition & $53.3(1)$ & 0.00 & & repetition & $57.3(1)$ & 0.00 \\
\hline
\end{tabular}

Base models were $\operatorname{lmer}(\mathrm{X} \sim\{$ vowel length $\}+$ repetition $+(1 \mid$ word $))$. $/ \mathrm{b} /$ productions include only positive VOTs (no prevoicing).

only productions with positive VOTs were included. Thus, any differences found are not due to some individuals using negative VOT and others not. Note that this may underestimate individual differences. A random intercept by word was also included to model potential differences in VOT according to word-level factors like neighbourhood density (Goldinger and Summers, 1989; Fox et al., 2015). We examined the improvement to model fit of including the random talker intercepts using a likelihood ratio test $\left(\chi^{2}\right)$ comparing models with just the random word intercept and models including both intercepts (see also Kliegl et al., 2011, for discussion of using random effects to examine individual differences). Finally, to test whether individuals varied in how their productions were affected by speaking rate and repetition, we included random slopes by participants for each. Significance of these slopes was tested by likelihood ratio tests by comparing intercept-only models to models containing each of the random slopes in turn. Correlations between random effects were not fit in any of the models. Significance of the fixed effects was determined with a Wald test (fixed effects are reported for models which include all the random intercepts and slopes). Results of the model comparisons are given in Table 3 .

Table 3 shows that when controlling for repetition and where possible speaking rate, there were significant talker differences in: VOT for both $/ \mathrm{p} /$ productions $\left(\chi^{2}[1]=\right.$ $210.1, p<0.005)$ and $/ \mathrm{b} /$ productions $\left(\chi^{2}[1]=66.6, p<0.005\right)$; onset $\mathrm{f} 0$ for $/ \mathrm{b} /$ productions $\left(\chi^{2}[1]=4.3, p=0.04\right)$; but not vowel duration. Note that our measures of onset f0 and vowel duration have already factored out most of the between-talker differences by making the measures relative to individual talkers' means across categories. What is being tested here is whether talkers differ in the degree to which voicing category perturbs their onset $\mathrm{f} 0$ or vowel duration. Thus, talker differences in mean $\mathrm{f0}$ and speaking rate have been eliminated. These results confirm previous findings that English-speaking adults differ in their use of VOT to signal a voicing contrast and extend it to positive VOTs for $/ \mathrm{b} /$ productions as well as to onset $\mathrm{f0}$ for $/ \mathrm{b} /$ productions.

The models provided evidence that talkers differed in the effect of repetition on their productions for onset $\mathrm{f} 0 \mathrm{for} / \mathrm{p} /$ productions $\left(\chi^{2}[1]=121.6, p<0.005\right)$ and $/ \mathrm{b} / \mathrm{pro}-$ ductions $\left(\chi^{2}[1]=25.8, p<0.005\right)$ and vowel duration for $/ \mathrm{p} /$ productions $\left(\chi^{2}[1]=53.3\right.$, 


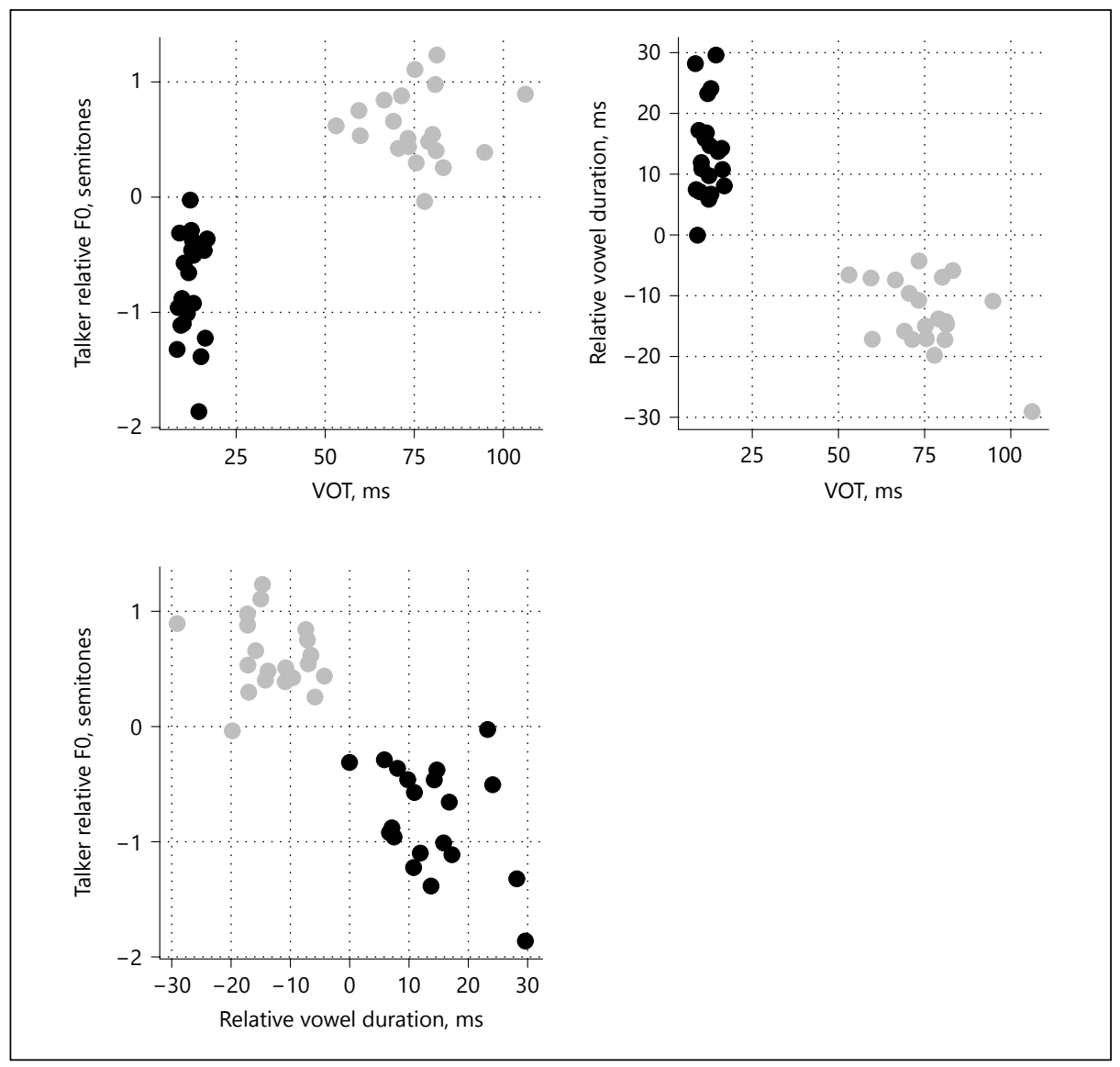

Fig. 4. Talker means for each voicing category for VOT, final-voicing-and-talker-relative vowel duration and talker-relative f0. Black circles are /b/ productions, and grey circles are /p/ productions.

$p<0.005)$ and $/ \mathrm{b} /$ productions $\left(\chi^{2}[1]=57.3, p<0.005\right)$. In the other cases the model estimates indicated that there was essentially no variation by talkers. Talkers also differed in the effect of speaking rate (vowel duration) only on onset $\mathrm{f0} f$ for $/ \mathrm{p} /$ productions $\left(\chi^{2}[1]=8.8, p<0.005\right)$ and $/ \mathrm{b} /$ productions $\left(\chi^{2}[1]=4.5, p=0.03\right)$.

Analysis of fixed effects for the models found that at slower speaking rates (longer vowels) VOTs were longer for $/ \mathrm{p} /$ productions $(\beta=2.24, \mathrm{SE}=0.85, t=2.64, p=0.01)$ while repetition reduced $\mathrm{f} 0 \mathrm{for} / \mathrm{p} /$ productions $(\beta=-0.59, \mathrm{SE}=0.20, t=2.87, p<$ $0.005)$ and $/ \mathrm{b} /$ productions $(\beta=-0.33, \mathrm{SE}=016, t=2.02, p=0.04)$.

Given the significant individual differences found in these analyses, we now turn to the question of how these cues pattern together both within categories and across talkers.

\subsection{Talker Means and Token-by-Token Deviations}

To test whether there was a relationship between the cues within talkers, we computed the mean VOT, onset $\mathrm{f} 0$ and relative vowel duration for each talker and each voicing category (Fig. 4). To test whether there were relationships that could not be 
explained by talker differences we computed the deviances from these means for each production. This allowed us to separate out variation in each cue that was due to differences in voicing and talker from variation that was not. If we observe relationships between cues that are not due to voicing or talker, we could more safely characterize this variation as arising due to intrinsic factors or conversely to token-by-token compensation.

To test these relationships statistically, we built on the individual difference models constructed in Section 3.3 above. To each model we added fixed effects of the talker means and deviations for the other 2 cues. For example, the model predicting VOT for $/ \mathrm{p} /$ productions had a fixed effect of mean onset f0 for each talker's /p/ productions as well as a fixed effect for the deviations from those means and a fixed effect of mean relative vowel duration for each talker's $/ \mathrm{p} /$ productions as well as a fixed effect for the deviations from those means. As before, because the negative VOT productions could be different from positive VOT productions and because there were relatively few negative VOTs, we included only productions with positive VOTs in the analysis. This means that for talkers with some negative VOT values, the mean VOT of /b/ productions does not reflect those negative VOTs. Therefore this is again a conservative estimate of the relationship between the cues. The random effects structure was expanded to include a random slope by participant for each of the deviation measures. The random slope for repetition by participant was removed from the models for VOT because the previous models of individual difference found the variance by talkers was near zero and thus increased model complexity without improving fit (see Barr et al., 2013, and Matuschek et al., 2015, for discussion of when to include random effects). Significance of fixed effects was tested using a Wald test on the $t$ statistic. Collinearity between all fixed effects was tested using kappa (the condition number) using the collin.fnc function in the languageR package (Baayen, 2009; R Core Team, 2016) and found to be very low in both the $/ \mathrm{b} /$ productions $(\kappa=1.79)$ and the $/ \mathrm{p} /$ productions $(\kappa=$ 1.97).

Results of the models for VOT are found in Table 4 . The model for $/ \mathrm{p} /$ productions found a negative relationship between VOT and vowel duration mean $(\beta=-5.15, \mathrm{SE}=$ $2.17, t=2.38, p=0.02$ ). Since vowels following voiceless stops are on average shorter than those following voiced stops, this means that talkers with on average more prototypical vowel duration (after taking into account the talker's mean vowel duration) for $/ \mathrm{p} /$ also produce more prototypical VOTs. Additionally, vowel duration deviation and VOT had a positive relationship $(\beta=1.51, \mathrm{SE}=0.58, t=2.6, p=0.01)$. In other words, productions that were longer than the talkers' category means also had longer VOTs. The model for $/ \mathrm{b} /$ productions found no relationship between talker mean vowel duration and VOT but a negative relationship between vowel duration deviation and $\operatorname{VOT}(\beta=-0.57, \mathrm{SE}=0.22, t=2.61, p=0.01)$ indicating that productions with vowels longer than the talker's mean had shorter VOTs. Together these results indicate that talkers with on average more prototypical vowel duration for $/ \mathrm{p} /$ productions produce more prototypical VOTs and that decreased speaking rate results in more prototypical productions of VOT for both $/ \mathrm{p} /$ and $/ \mathrm{b} /$ productions.

The models for both $/ \mathrm{p} /$ and $/ \mathrm{b} /$ productions found no relationships between VOT and talker's mean onset f0 or the deviations from those means. Repetition did not influence VOT.

Two parallel models were constructed to examine onset f0. Results are in Table 5. The only reliable effect on onset $f 0$ was VOT deviation for $/ b /$ productions wherein 
Table 4. Model output from $\operatorname{lmer}(\mathrm{VOT} \sim$ vowel duration mean + vowel duration deviation + onset f0 mean + onset $\mathrm{f} 0$ deviation + repetition $+(1+$ vowel duration deviation + onset $\mathrm{f} 0$ deviation $\mid$ |talker $)+$ (1|word)) for data from each voicing category

\begin{tabular}{|c|c|c|c|c|c|}
\hline & & Estimate & SE & $t$ value & $p$ \\
\hline \multirow[t]{6}{*}{$/ \mathrm{p} /$} & Intercept & 74.94 & 3.08 & 24.36 & 0.00 \\
\hline & Vowel duration mean & -5.15 & 2.17 & -2.38 & 0.02 \\
\hline & Vowel duration deviation & 1.51 & 0.58 & 2.60 & 0.01 \\
\hline & Onset f0 mean & -1.20 & 2.50 & -0.48 & 0.63 \\
\hline & Onset f0 deviation & -1.05 & 1.11 & -0.94 & 0.35 \\
\hline & Repetition & -0.48 & 0.73 & -0.65 & 0.51 \\
\hline \multirow[t]{6}{*}{$/ \mathrm{b} /$} & Intercept & 12.23 & 0.66 & 18.40 & 0.00 \\
\hline & Vowel duration mean & -0.18 & 0.51 & -0.35 & 0.72 \\
\hline & Vowel duration deviation & -0.57 & 0.22 & -2.61 & 0.01 \\
\hline & Onset f0 mean & 0.08 & 0.56 & 0.15 & 0.88 \\
\hline & Onset f0 deviation & -0.53 & 0.32 & -1.66 & 0.10 \\
\hline & Repetition & 0.05 & 0.27 & 0.19 & 0.85 \\
\hline
\end{tabular}

Table 5. Model output from lmer (onset $\mathrm{f} 0 \sim$ vowel duration mean + vowel duration deviation + VOT mean + VOT deviation + repetition $+(1+$ vowel duration deviation + VOT deviation + repetition ||talker $)$ $+(1 \mid$ word $))$ for data from each voicing category (positive VOTs only)

\begin{tabular}{|c|c|c|c|c|c|}
\hline & & Estimate & SE & $t$ value & $p$ \\
\hline \multirow[t]{6}{*}{$/ \mathrm{p} /$} & Intercept & 0.52 & 0.09 & 5.56 & 0.00 \\
\hline & VOT mean & -0.08 & 0.06 & -1.31 & 0.19 \\
\hline & VOT deviation & -0.07 & 0.10 & -0.66 & 0.51 \\
\hline & Vowel duration mean & -0.04 & 0.06 & -0.69 & 0.49 \\
\hline & Vowel duration deviation & 0.05 & 0.06 & 0.86 & 0.39 \\
\hline & Repetition & -0.59 & 0.21 & -2.88 & 0.00 \\
\hline \multirow[t]{6}{*}{$/ \mathrm{b} /$} & Intercept & -0.86 & 0.12 & -7.26 & 0.00 \\
\hline & VOT mean & -0.06 & 0.09 & -0.59 & 0.56 \\
\hline & VOT deviation & -0.20 & 0.09 & -2.20 & 0.03 \\
\hline & Vowel duration mean & -0.12 & 0.09 & -1.26 & 0.21 \\
\hline & Vowel duration deviation & -0.05 & 0.09 & -0.55 & 0.58 \\
\hline & Repetition & -0.33 & 0.18 & -1.86 & 0.06 \\
\hline
\end{tabular}

longer VOTs occur with lower onset f0 ( $\beta=-0.02, \mathrm{SE}=0.09, t=2.20, p=0.03)$. This is in line with the raw correlations observed in Section 3.2 and is confirmed here after controlling for talker means and repetition. It is in the opposite direction from the effect reported in Dmitrieva et al. (2015) for English and in the opposite direction from an intrinsic effect. It is in the same direction as Kirby and Ladd (2015) report for Italian short-lag stops. Repetition decreased onset f0 significantly in /p/ productions $(\beta=-0.59, \mathrm{SE}=0.21, t=-2.88, p<0.005)$ and marginally in $/ \mathrm{b} /$ productions $(\beta=-0.33, \mathrm{SE}=0.18, t=1.86, p=0.06)$. 
Table 6. Model output from lmer(relative vowel duration $\sim$ onset $\mathrm{f} 0$ mean + onset $\mathrm{f} 0$ deviation + VOT mean + VOT deviation + repetition + $(1+$ onset f0 deviation + VOT deviation ||talker $)+(1 \mid$ word $))$ for data from each voicing category (positive VOTs only)

\begin{tabular}{|c|c|c|c|c|c|}
\hline & & Estimate & SE & $t$ value & $p$ \\
\hline \multirow[t]{6}{*}{$/ \mathrm{p} /$} & Intercept & -12.10 & 1.42 & -8.55 & 0.00 \\
\hline & VOT mean & -1.82 & 1.41 & -1.29 & 0.20 \\
\hline & VOT deviation & 5.10 & 2.49 & 2.05 & 0.04 \\
\hline & Onset f0 mean & 0.50 & 1.47 & 0.34 & 0.73 \\
\hline & Onset f0 deviation & 1.62 & 1.55 & 1.05 & 0.30 \\
\hline & Repetition & 3.50 & 3.08 & 1.14 & 0.26 \\
\hline \multirow[t]{6}{*}{$/ \mathrm{b} /$} & Intercept & 13.30 & 2.37 & 5.61 & 0.00 \\
\hline & VOT mean & -0.12 & 1.43 & -0.08 & 0.93 \\
\hline & VOT deviation & -3.86 & 3.47 & -1.11 & 0.27 \\
\hline & Onset f0 mean & -2.35 & 1.53 & -1.53 & 0.13 \\
\hline & Onset f0 deviation & -0.01 & 1.79 & 0.00 & 1.00 \\
\hline & Repetition & 2.47 & 2.20 & 1.12 & 0.26 \\
\hline
\end{tabular}

The third set of models examined vowel duration. As before, this measure was final voicing and talker mean corrected. Results are summarized in Table 6. For $/ \mathrm{p} /$ productions vowel duration was significantly affected by VOT deviation in the same way that we saw in the VOT model. In other words, longer than average VOTs were associated with longer than average vowel durations $(\beta=5.10, \mathrm{SE}=$ $2.49, t=2.05, p=0.04)$, likely due to speaking rate. Repetition did not affect vowel duration.

In summary, we found that talker means revealed that some talkers spoke with more prototypical values: talkers with shorter average vowels for $/ \mathrm{p} /$ productions had longer VOTs. For $/ \mathrm{b} /$ productions, there were no relationships between talker means for onset $\mathrm{f0}$ or vowel duration and VOT.

Analysis of deviations from talker means found that on a token-by-token basis, a slower speaking rate (longer vowels) led to longer/p/VOTs and shorter /b/VOTs. We also found that for $/ \mathrm{b} /$ productions, lower f0 was associated with longer VOTs, which is inconsistent with an intrinsic effect. Thus, we found evidence that, other than speaking rate effects, cues seem to be correlated more at the level of talkers than within categories on a token-by-token basis.

\subsection{Individual Differences in Contrast Signalling}

In the previous sections we found significant differences in how talkers produced each category, and these differences were consistent with some talkers speaking more carefully or hyperarticulating. However, we only examined the behaviour of talkers within a single category and not how they signalled the contrast between the categories. In this section we test whether there is a relationship between the degree to which individual talkers rely on one cue versus another cue to signal the contrast. Talkers who produce one cue more prototypically may produce another cue more ambiguously (as in Shultz et al., 2012). Conversely if some talkers are speaking more carefully, they may produce all cues more prototypically than other speakers. 


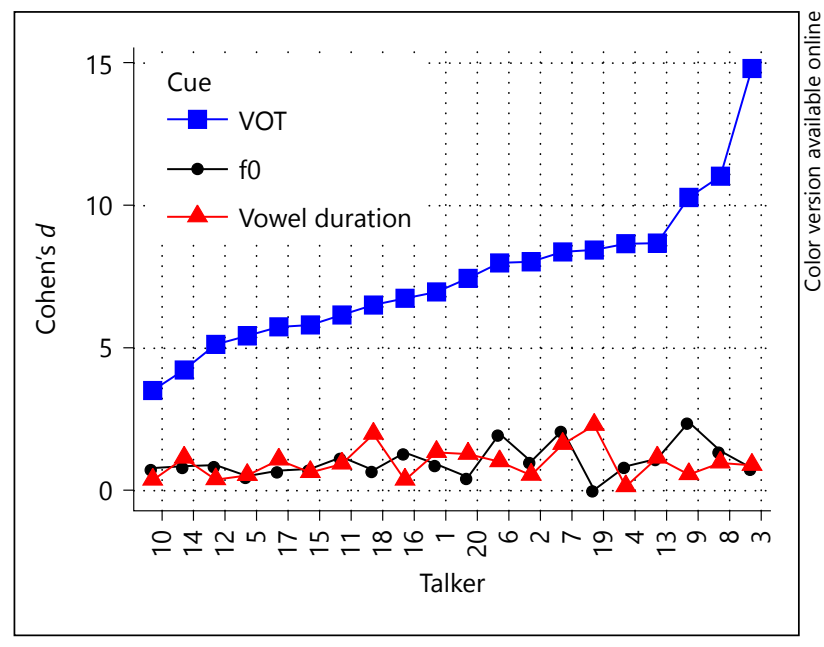

Fig. 5. Cohen's $d$ values of each cue for each talker.

To determine how consistently each cue was produced by each speaker, we quantified the amount of overlap between the categories. The amount of overlap between categories can be used as a metric of how precisely that cue conveys the contrast (Nearey and Hogan, 1986; Clayards, 2008; Noiray et al., 2014) and has been shown to influence perception (Newman et al., 2001; Clayards et al., 2008). In the extreme, a cue for which the distributions of 2 categories are entirely overlapping does not convey any information about the contrast. On the other hand, a cue for which there is no overlap between the categories distinguishes the contrast perfectly. The amount of overlap was quantified using the Cohen's $d$ (Green and Swets, 1966) which was calculated by Equation 1:

$$
d=\frac{\mu_{\mathrm{nb}}-\mu_{\mathrm{n} p "}}{\sigma_{\mathrm{kb}}+\sigma_{\mathrm{pp} "}}
$$

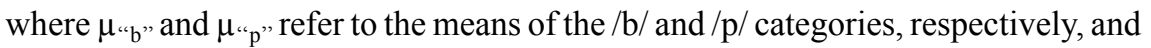
$\sigma$ "b" and $\sigma$ " $\mathrm{p}$ " refer to the standard deviations of the $/ \mathrm{b} /$ and $/ \mathrm{p} /$ categories, respectively.

The Cohen's $d$ values were calculated for each individual and each cue separately and are shown in Figure 5. Values for VOT were calculated on positive VOTs only to be more comparable to Shultz et al. (2012).

For each talker, the Cohen's $d$ value for VOT is much greater than any of the other cues. There is also considerable variability among speakers in the values for VOT but much less in the values of other cues. Correlations between the Cohen's $d$ values of each cue found no significant relationships (Table 7). To more directly compare our results to those of Shultz et al. (2012), we also performed a linear discriminant analysis using the lda() function of the MASS package in R. For each talker we computed the linear discriminant analysis coefficient for each cue. We then compared the correlations between the coefficients for each cue pair. Unlike Schultz et al. who found a significant negative correlation between onset $\mathrm{f0}$ and VOT, we found a positive correlation that was marginally significant $(R=0.408, p=0.075)$. We also found a positive correlation between vowel duration and onset f0 coefficients $(R=0.510, p=0.021)$. 
Table 7. Correlations between Cohen's $d$ values or linear discriminant analysis coefficients calculated for each talker and each cue

\begin{tabular}{lccc}
\hline & Pearson $R$ & $p$ & $N$ \\
\hline Cohen's $d$ & & & \\
VOT/f0 & 0.270 & 0.249 & 20 \\
VOT/vowel duration & 0.109 & 0.646 & 20 \\
Vowel duration/f0 & -0.192 & 0.417 & 20 \\
\hline Linear discriminant analysis & & & \\
VOT/f0 & 0.408 & 0.075 & 20 \\
VOT/vowel duration & 0.352 & 0.128 & 20 \\
Vowel duration/f0 & 0.510 & 0.021 & 20 \\
\hline
\end{tabular}

\section{Discussion}

We investigated 3 cues to voicing in word-initial labial stops. As expected, voiceless stops had longer VOT, higher f0 and shorter following vowels than voiced stops. Of interest, however, were the relationships within each voicing category and within and between talkers. In other words, we were interested in whether the variation was systematic on a token-by-token basis and could be attributed to factors intrinsic to the production system, or whether it was systematic on a talker-by-talker basis and could be attributed to individual differences. Other than speaking rate effects, our evidence was more in favour of the latter.

We found no evidence for intrinsic relationships between the cues that were likely to be traced back to articulatory interactions (within-category correlations in the same direction as between-category correlations as in Fig. 1a). Even VOT and f0, which have been argued to be related for physiological reasons at the level of the musculature of the larynx (Hombert et al., 1979; Ohde, 1984), only displayed within-category token-by-token correlations for the $/ \mathrm{b} /$ productions which were in the opposite direction from the overall pattern; in other words, they were not in the direction predicted by the physiological mechanism. Of course, lack of an effect should be treated with caution, especially given other results in the literature. However, some previous results should also be treated with caution, as they did not account for individual differences in mean values.

We also found little evidence that talkers were compensating for ambiguous cues in one dimension with prototypical cues in the other dimension (i.e. within-category correlations in the opposite direction as between-category correlations as in Fig. 1c; however, note that very few VOT values could be considered ambiguous, weakening the possibility of testing this hypothesis). The one exception is the VOT/onset f0 relationship for $/ \mathrm{b} /$ productions discussed above. Instead, the token-by-token relationships we observed can be best understood as arising from more hyperarticulation with slower speaking rate. This was observed in the vowel duration effects on VOT. With slower speaking rate (longer vowels), VOT was longer for $/ \mathrm{p} /$ productions and shorter for $/ \mathrm{b} /$ productions. This is consistent with previous studies that reported longer VOTs for (long-lag) voiceless stops with slower speaking rate (Kessinger and Blumstein, 1997, 1998; Miller et al., 1986; Port, 1981); however, it is in contrast to previous findings that 
reported no changes in VOT for (short-lag) voiced stops (Kessinger and Blumstein, 1997) or an increase in VOT for (short-lag) voiced stops (Miller et al., 1986; Boucher, 2002) with slower speaking rate. Previous results had also reported that the ratio of VOT to syllable duration was constant across syllable durations (i.e. ratio-syllable duration had a slope of zero; Boucher, 2002). A simple regression on our data found this not to be the case. There were significant negative slopes for both $/ \mathrm{b} /$ and $/ \mathrm{p} / \mathrm{mod}-$ els $(p<0.05)$. The shorter VOTs in voiced stops with slower speaking rates and the fact that the VOTs could not be fully explained by vowel duration suggest that our talkers were deliberately hyperarticulating the VOT cue. Recent studies have found that voiceless stops are produced with longer VOTs when a minimal pair is salient (Baese-Berk and Goldrick, 2009) even after controlling for speaking rate (Buzz et al., 2014). Like many classic studies, our words were also produced in the presence of salient minimal pairs which might have triggered this targeted hyperarticulation.

Previous studies had found significant individual talker differences in the values of individual cues (e.g. Allen et al., 2003; Newman et al., 2001). Within VOT it has been shown that some of these differences may be systematic across stop categories (Chodroff et al., 2015; Scobbie, 2006). We extended this to multiple cues to the same contrast. The analyses reported in Table 2 also showed that talkers differed from each other significantly in VOT for both $/ \mathrm{b} /$ and $/ \mathrm{p} /$ (controlling for speaking rate), and $\mathrm{f0}$ for /b/ (controlling for speaking rate and talker mean f0). Furthermore, these differences were systematic. Some talkers used more prototypical values (longer VOT, shorter vowels for $/ \mathrm{p} /$; shorter VOT, longer vowels for $/ \mathrm{b} /$ ) than others. This suggests that some of the variation between talkers, at least in cues to voicing, is due to speaking style or degree of hyperarticulation. Studies of clear versus conversational style speech have generally focused on global variables (see Smiljanic and Bradlow, 2009, for a review). Krause and Braida (2009) examined specific phonetic cues and found mixed results for the effect of clear speech on VOT; however, this study only included 2 talkers. Thus, more would be required before classifying some speakers as using "clear speech." What is also unclear from this data is whether the differences between talkers seen here are global properties of these talkers or simply reflect how they decided to act in this particular task. Recent work on day-to-day fluctuations in talker VOT extracted from a large corpus suggests that individual talkers' VOTs do shift substantially from day to day while often remaining stable over longer time scales (Sonderegger, 2015). The individuals in this study were not from a homogenous dialect region either. It is possible that the differences we observed are due to dialect differences (see Scobbie, 2006, for examples of dialect differences in Scottish VOT). Nonetheless, studies with homogenous dialect groups have also found individual differences (e.g. Hazan et al., 2011). Furthermore, the fact that the differences observed here line up with patterns of hyperarticulation makes the dialect explanation less plausible.

As expected, our analysis of Cohen's $d$ (degree of overlap between the categories) found that VOT was by far the strongest cue to this contrast. Interestingly we also found that it varied much more between talkers in degree of overlap than the other 2 cues. This suggests that while all cues are affected by speaking style, the strongest cues may be affected most while secondary cues are more robust. In line with this observation, Lisker and Abrahmson (1967) found that differences between stop voicing categories decreased in carrier phrases relative to citation form speech, suggesting more hypo-articulation in carrier phrases. Ohde (1984) also found that VOT was more affected than f0. An intriguing implication of this pattern is a possible role in 
sound change. One theory about the origin of tonogenesis is that it arises from differences in $\mathrm{f0}$ due to voicing taking over the contrastive role from VOT (Hombert et al., 1979 ) in a process often called phonologization. Hypoarticulation of high-frequency words has long been hypothesized to be a driver of sound change (Lindblom et al., 1995) along with enhancement of secondary cues (Kirby, 2013). Kirby (2010, 2013) argues through computational simulations that both loss of precision in the primary cue (decrease in Cohen's $d$ ) and enhancement of a secondary cue (increase in Cohen's $d$ ) is required to account for phonologization. He proposes a probabilistic enhancement hypothesis in which cues are enhanced over time in direct proportion to their precision as measured by the Cohen's $d$. Thus, if the differential effect of hyperarticulation on precision between VOT and onset f0 observed here is also in effect in high- versus low-frequency words (in English as well as in languages undergoing tonogenesis like Seoul Korean), then high-frequency words provide exactly the conditions for Kirby's probabilistic enhancement of f0. Bang et al. (2015) tested this prediction by examining word frequency effects in Seoul Korean and found evidence that enhancement of f0 proceeds in parallel with weakening of VOT in high-frequency words over time, just as predicted. Future work should test whether onset $\mathrm{f} 0$ as a cue to voicing and secondary cues in general are more robust to hypoarticulation than primary cues and in particular if word frequency has the effect of reducing differences in precision between cues.

\section{Conclusions}

We investigated multiple cues to the word-initial /p/-/b/ contrast in English across tokens and across talkers. We found that within-category, token-by-token variability was best characterized as more hyperarticulated productions for slower speaking rates. After accounting for differences in talker means, the only correlation between cues on a token-by-token basis was a negative correlation between onset $\mathrm{f0}$ and VOT for $/ \mathrm{b} /$ productions. We also found significant intertalker variation. This variation was systematic across cues such that some talkers produced more prototypical/hyperarticulated speech in multiple dimensions but VOT varied most between talkers in degree of hyperarticulation. Future research should determine whether these talker differences extend to other sound contrasts within the same individuals.

\section{Acknowledgements}

Data collection was supported by NIH research grant DC-005071 to Michael K. Tanenhaus and Richard N. Aslin and by FQRSC grant 145433 to the author.

\section{References}

Allen JS, Miller JL, DeSteno D (2003): Individual talker differences in voice-onset-time. J Acoust Soc Am 113:544522.

Baayen HR (2009): LanguageR. R package. http://CRAN.R-project.org/package=language R.

Baese-Berk M, Goldrick M (2009): Mechanisms of interaction in speech production. Lang Cogn Process 24:527554.

Bailey PJ, Summerfield Q (1980): Information in speech: observations on the perception of [s]-stop clusters. J Exp Psychol Hum Percept Perform 6:536-563. 
Bang H-Y, Sonderegger M, Kang Y, Clayards M, Yoon T-J (2015): The effect of word frequency on the time-course of tonogenesis in Seoul Korean. Proceedings of the 18th International Congress of Phonetic Sciences, Glasgow.

Barr DJ, Levy R, Scheepers C, Tily HJ (2013): Random effects structure for confirmatory hypothesis testing: keep it maximal. J Mem Lang 68:255-278.

Bates D, Maechler M, Bolker B, Walker S (2014): lme4: linear mixed-effects models using Eigen and S4. R package version 1.1-7. http://CRAN.R-project.org/package=lme4

Bertelson P, Vroomen J, de Gelder B (2003): Visual recalibration of auditory speech identification: a McGurk aftereffect. Psychol Sci 14:592-597.

Boersma P, Weenink D (2011): Praat: doing phonetics by computer (version 4.6.09). www.praat.org.

Boucher VJ (2002): Timing relations in speech and the identification of voice-onset times: a stable perceptual boundary for voicing categories across speaking rates. Percept Psychophys 64:121-130.

Buzz E, Jaeger F, Tanenhaus MK (2014): Contextual confusability leads to targeted hyperarticulation. Proceedings of the 36th Annual Conference of the Cognitive Science Society, Quebec City.

Chodroff E, Godfrey J, Khudanpur S, Wilson C (2015): Structured variability in acoustic realization: a corpus study of voice onset time in American English stops. Proceedings of the 18th International Congress of Phonetic Sciences, Glasgow.

Clayards M (2008): The Ideal Listener: Making Optimal Use Of Acoustic Cues For Speech Perception; PhD thesis, University of Rochester.

Clayards M, Tanenhaus MK, Aslin RN, Jacobs RA (2008): Perception of speech reflects optimal use of probabilistic speech cues. Cognition 108:804-809.

Cole J, Kim H, Choi H, Hasegawa-Johnson M (2007): Prosodic effects on acoustic cues to stop voicing and place of articulation: evidence from radio news speech. J Phonet 35:180-209.

Dmitrieva O, Llanos F, Shultz AA, Francis AL (2015): Phonological status, not voice onset time, determines the acoustic realization of onset f0 as a secondary voicing cue in Spanish and English. J Phonet 49:77-95.

Eisner F, McQueen JM (2005): The specificity of perceptual learning in speech processing. Percept Psychophys 67:224-238.

Ferguson SH (2004): Talker differences in clear and conversational speech: vowel intelligibility for normal-hearing listeners. J Acoust Soc Am 116:2365-2373.

Fox NP, Reilly M, Blumstein SE (2015): Phonological neighborhood competition affects spoken word production irrespective of sentential context. J Mem Lang 83:97-117.

Goggin JP, Thompson CP, Strube G, Simental LR (1991): The role of language familiarity in voice identification Mem Cogn 19:448-458.

Goldinger S, Summers W (1989): Lexical neighborhoods in speech production: a first report. Research on Speech Perception Progress Report. Psychology Department, Speech Research Laboratory, Indiana University, vol 15 , pp 331-342.

Green DM, Swets JA (1966): Signal Detection Theory and Psychophysics. New York, Wiley.

Hazan V, Baker R, Lee WS, Zee E (2011): Is consonant perception linked to within-category dispersion or acrosscategory distance. Proceedings of the 17th International Congress of Phonetic Sciences, Hong Kong, pp $839-842$.

Hazan V, Markham D. (2004): Acoustic-phonetic correlates of talker intelligibility for adults and children. J Acoust Soc Am 116:3108-3118.

Holt L, Lotto A, Kluender K (2001): Influence of fundamental frequency on stop-consonant voicing perception: a case of learned covariation or auditory enhancement? J Acoust Soc Am 109:764-774.

Hombert JM, Ohala JJ, Ewan WG (1979): Phonetic explanations for the development of tones. Language 55:3758.

Hoole P, Honda K, Murano E, Fuchs S, Pape D (2004): Cricothyroid activity in consonant voicing and vowel intrinsic pitch. Proceedings of the Conference on Voice Physiology and Biomechanics, Marseille.

Hoole P, Honda K (2011): Automaticity vs feature-enhancement in the control of segmental F0; in Clements GN, Ridouane R (eds): Where Do Phonological Features Come from: Cognitive, Physical and Developmental Bases of Distinctive Speech Categories. Amsterdam, Benjamins Publishing Company, pp 131-171.

House AS, Fairbanks G (1953): The influence of consonant environment upon the secondary acoustical characteristics of vowels. J Acoust Soc Am 25:105-113.

Johnson K, Ladefoged P, Lindau M (1993): Individual differences in vowel production. J Acoust Soc Am 94:701714.

Kessinger RH, Blumstein SE (1997): Effects of speaking rate on voice-onset time in Thai, French and English. J Phonet 25:143-168.

Kessinger RH, Blumstein SE (1998): Effects of speaking rate on voice-onset time and vowel production: some implications for perception studies. J Phonet 26:117-128.

Kingston J, Diehl RL (1994): Phonetic knowledge. Language 70:419-454

Kingston J, Diehl RL, Kirk CJ, Castleman WA (2008): On the internal perceptual structure of distinctive features: the [voice] contrast. J Phonet 36:28-54.

Kirby J (2010): Cue Selection and Category Restructuring in Sound Change; PhD thesis, University of Chicago.

Kirby J (2013): The role of probabilistic enhancement in phonologization; in Yu A (ed): Origins of Sound Patterns: Approaches to Phonologization. Oxford, Oxford University Press, pp 228-246. 
Kirby JP, Ladd DR (2015): Stop voicing and f0 perturbations: evidence from French and Italian. Proceedings of the 18th International Congress of Phonetic Sciences, Glasgow.

Kirby JP, Ladd DR (2016): Effects of obstruent voicing on vowel F0: evidence from "true voicing" languages. J Acoust Soc Am 140:2400-2411.

Kliegl R, Wei P, Dambacher M, Yan M, Zhou X (2011): Experimental effects and individual differences in linear mixed models: estimating the relationship between spatial, object, and attraction effects in visual attention. Front Psychol 1:238-238.

Kohler KJ (1979): Dimensions in the perception of fortis and lenis plosives. Phonetica 36:332-343.

Krause JC, Braida LD (2009): Evaluating the role of spectral and envelope characteristics in the intelligibility advantage of clear speech. J Acoust Soc Am 125:3346-3357.

Lehiste I, Peterson GE (1961): Some basic considerations in the analysis of intonation. J Acoust Soc Am 33:419-425.

Lindblom B, Guion S, Hura S, Moon S-J, Willerman R (1995): Is sound change adaptive? Riv Linguist 7:5-36.

Lisker L (1986): "Voicing" in English: a catalogue of acoustic features signaling /b/ versus /p/ in trochees. Lang Speech 29:3-11.

Lisker L, Abrahmson AS (1964): Cross-language study of voicing in initial stops. Word 20:384-422.

Lisker L, Abrahmson AS (1967): Some effect of context on voice onset time in English stops. Lang Speech 10:1-28.

Mack M (1982): Voicing-dependent vowel duration in English and French: monolingual and bilingual production. J Acoust Soc Am 71:173-178.

Mann VA, Repp BH (1980): Influence of vocalic context on perception of the /sh/-/s/ distinction. Percept Psychophys 28:213-228.

Matuschek H, Bates D, Kliegl R, Vasishth S, Baayen H (2015): Balancing type I error and power in linear mixed models. http://arxiv.org/abs/1511.01864.

McMurray B, Clayards MA, Tanenhaus MK, Aslin RN (2008): Tracking the time course of phonetic cue integration during spoken word recognition. Psychon Bull Rev 15:1064-1071.

McMurray B, Jongman A (2011): What information is necessary for speech categorization? Harnessing variability in the speech signal by integrating cues computed relative to expectations. Psychol Rev 118:219.

Miller JL, Green KP, Reeves A (1986): Speaking rate and segments: a look at the relation between speech production and speech perception for the voicing contrast. Phonetica 43:106-115.

Nearey T (1997): Speech perception as pattern recognition. J Acoust Soc Am 101:3241-3254.

Nearey T, Hogan JT (1986): Phonological contrast in experimental phonetics: relating distributions of production data to perceptual categorization curves; in Ohala JJ, Jaeger JJ (eds): Experimental Phonology. Orlando, Academic Press, pp 121-162.

Newman RS, Clouse SA, Burnham JL (2001): The perceptual consequences of within-talker variability in fricative production. J Acoust Soc Am 109:1181-1196.

Noiray A, Iskarous K, Whalen DH (2014): Variability in English vowels is comparable in articulation and acoustics. Lab Phonol 5:271-288.

Norris D, McQueen JM, Cutler A (2003): Perceptual learning in speech. Cogn Psychol 47:204-238.

Nygaard LC, Pisoni DB (1998): Talker-specific learning in speech perception. Percept Psychophys 60:355-376.

Ohde RN (1984): Fundamental frequency as an acoustic correlate of stop consonant voicing. J Acoust Soc Am 75:224.

Port RF (1981): Linguistic timing factors in combination. J Acoust Soc Am 69:262-274.

Port RF, Dalby J (1982): Consonant/vowel ratio as a cue for voicing in English. Percept Psychophys 32:141152.

Raphael LJ (2005): Acoustic cues to the perception of segmental phonemes; in Pisoni D, Remez R (eds):The Handbook of Speech Perception. Wiley-Blackwell, Oxford, pp 182-206.

R Core Team (2016): R: A language and environment for statistical computing. R Foundation for Statistical Computing, Vienna, Austria. https://www.R-project.org/.

Repp BH (1982): Phonetic trading relations and context effects: new experimental evidence for a speech mode of perception. Psychol Bull 92:81-110.

Scobbie JM (2006): Flexibility in the face of incompatible English VOT systems; in Goldstein L, Whalen DH, Best CT (eds): Laboratory Phonology 8: Varieties of Phonological Competence. Phonology and Phonetics 4-2. Berlin, Mouton de Gruyter, pp 367-392.

Shultz AA, Francis AL, Llanos F (2012): Differential cue weighting in perception and production of consonant voicing. J Acoust Soc Am 132:EL95-EL101.

Slis IH, Cohen A (1969): On the complex regulating the voiced-voiceless distinction. Lang Speech 12:80-102.

Smiljanić R, Bradlow AR (2009): Speaking and hearing clearly: talker and listener factors in speaking style changes. Linguist Lang Compass 3:236-264.

Sonderegger M (2015): Trajectories of voice onset time in spontaneous speech on reality TV. Proceedings of the 18th International Congress of Phonetic Sciences, Glasgow.

Sussman HM, Fruchter D, Hilbert J, Sirosh J (1998): Linear correlates in the speech signal: the orderly output constraint. Behav Brain Sci 21:241-259.

Theodore RM, Miller JL (2010): Characteristics of listener sensitivity to talker-specific phonetic detail. J Acoust Soc Am 128:2090-2099.

Theodore RM, Miller JL, DeSteno D (2009): Individual talker differences in voice-onset-time: contextual influences. J Acoust Soc Am 125:3974-3982. 
Theodore RM, Myers EB, Lomibao JA (2015): Talker-specific influences on phonetic category structure. J Acoust Soc Am 138:1068-1078.

Toscano JC, McMurray B (2010): Cue integration with categories: weighting acoustic cues in speech using unsupervised learning and distributional statistics. Cogn Sci 34:434-464.

Toscano JC, McMurray B (2012): Cue-integration and context effects in speech: evidence against speaking-rate normalization. Attent Percept Psychophys 74:1284-1301.

Umeda N (1981): Influence of segmental factors on fundamental frequency in fluent speech. J Acoust Soc Am $70: 350-355$.

Wang W, Fillmore C (1961): Intrinsic cues and consonant perception. J Speech Hear Res 4:130-136. 